\title{
Bioaugmentation of UASB reactors with immobilized Sulfurospirillum barnesii for simultaneous selenate and nitrate removal
}

\author{
Markus Lenz • Anne Marie Enright • \\ Vincent O'Flaherty • Adriaan C. van Aelst . \\ Piet N. L. Lens
}

Received: 16 December 2008 /Revised: 11 February 2009/Accepted: 12 February 2009/Published online: 21 March 2009

(C) The Author(s) 2009. This article is published with open access at Springerlink.com

\begin{abstract}
Whole-cell immobilization of selenate-respiring Sulfurospirillum barnesii in polyacrylamide gels was investigated to allow the treatment of selenate contaminated $\left(790 \mu \mathrm{g} \mathrm{Se} \times \mathrm{L}^{-1}\right)$ synthetic wastewater with a high molar

Electronic supplementary material The online version of this article (doi:10.1007/s00253-009-1915-x) contains supplementary material, which is available to authorized users.
\end{abstract}

\section{Lenz $\cdot$ P. N. L. Lens}

Sub-Department of Environmental Technology,

Wageningen University,

Bomenweg 2,

6700 EV Wageningen, The Netherlands

\section{Lenz}

Institute for Ecopreneurship,

University of Applied Sciences Northwestern Switzerland

(FHNW),

Gründenstrasse 40,

4132 Muttenz, Switzerland

A. M. Enright $\cdot$ V. O'Flaherty

Microbial Ecology Laboratory,

Department of Microbiology and Environmental Change Institute

(ECI), National University of Ireland,

Galway (NUI, Galway),

University Road,

Galway, Ireland

\author{
A. C. van Aelst \\ Wageningen Electron Microscopy Center, \\ Arboretumlaan 4, \\ 6703 BD Wageningen, The Netherlands \\ P. N. L. Lens $(\bowtie)$ \\ UNESCO-IHE Institute for Water Education, \\ Westvest 7, \\ 2611 AX Delft, The Netherlands \\ e-mail: Piet.Lens@wur.nl
}

excess of nitrate (1,500 times) and sulfate (200 times). Gelimmobilized $S$. barnesii cells were used to inoculate a mesophilic $\left(30^{\circ} \mathrm{C}\right)$ bioreactor fed with lactate as electron donor at an organic loading rate of $5 \mathrm{~g}$ chemical oxygen demand $(\mathrm{COD}) \times \mathrm{L}^{-1} \mathrm{day}^{-1}$. Selenate was reduced efficiently $(>97 \%)$ in the nitrate and sulfate fed bioreactor, and a minimal effluent concentration of $39 \mu \mathrm{g} \mathrm{Se} \times \mathrm{L}^{-1}$ was obtained. Scanning electron microscopy with energy dispersive X-ray (SEM-EDX) analysis revealed spherical bioprecipitates of $\leq 2 \mu \mathrm{m}$ diameter mostly on the gel surface, consisting of selenium with a minor contribution of sulfur. To validate the bioaugmentation success under microbial competition, gel cubes with immobilized S. barnesii cells were added to an Upflow Anaerobic Sludge Bed (UASB) reactor, resulting in earlier selenate ( 24 hydraulic retention times (HRTs)) and sulfate (44 HRTs) removal and higher nitrate/nitrite removal efficiencies compared to a nonbioaugmented control reactor. S. barnesii was efficiently immobilized inside the UASB bioreactors as the selenatereducing activity was maintained during long-term operation (58 days), and molecular analysis showed that $S$. barnesii was present in both the sludge bed and the effluent. This demonstrates that gel immobilization of specialized bacterial strains can supersede wash-out and out-competition of newly introduced strains in continuous bioaugmented systems. Eventually, proliferation of a selenium-respiring specialist occurred in the non-bioaugmented control reactor, resulting in simultaneous nitrate and selenate removal during a later phase of operation.

Keywords Denitrification - Whole-cell immobilization . Dissimilatory selenium reduction - Bioprecipitation . Drainage water treatment 


\section{Introduction}

Selenium contamination of soil and water is a problem of global importance. Although the ecotoxicological effects of selenium poisoning were documented in the western US already 30 years ago, a cost-effective solution to the problem has not yet been found and the threat to wildlife persists (Hamilton 2004; Presser and Luoma 2007; Wu 2004). Biological reduction processes are considered a promising approach to decontaminate large quantities of such agricultural drainage waters polluted with nitrate $(\sim 3.5 \mathrm{mM})$ and low concentrations of soluble selenium oxyanions (selenite and selenate, $\sim 3.5 \mu \mathrm{M}$; Oremland et al. 1999) because of their high selectivity toward the targeted oxyanions (Lenz et al. 2008b).

Denitrifying microorganisms have been proposed as key biocatalysts for the treatment of this type of (waste)waters due to the selenium oxyanion-reducing ability of both membrane bound and periplasmatic nitrate reductases (Sabaty et al. 2001). The specific activities for selenate reduction by nitrate reductases are, however, 15 to 518 times lower (Watts et al. 2005) and the affinity constants $\left(K_{\mathrm{M}}\right) 2.3$ times higher for selenate compared to nitrate reduction (Sabaty et al. 2001). Consequently, selenate is reduced by these enzymatic systems at low nitrate concentrations only (Frankenberger et al. 2004). One approach to achieve these sufficiently low nitrate levels, thus enabling selenate reduction, is a two-compartment reactor system, implemented in, e.g. the algal-bacterial selenium reduction system (Amweg et al. 2003). In the first compartment, nitrate levels are reduced in a high rate pond by microalgal assimilation, whereas selenate is biologically reduced to $<100 \mu \mathrm{g} / \mathrm{L}$ by bacteria in anaerobic ponds of the second compartment (Green et al. 2003). However, space prerequisites for these reduction steps are high, and further treatment steps (dissolved air flotation and slow sand filtration) are required to remove algal biomass and remaining selenium particles prior to the discharge of the effluent to the environment (Amweg et al. 2003).

Selenate-respiring microorganisms contain specific selenate reductases not competitively inhibited by nitrate (Schröder 1997). This specificity of the selenate-reducing enzymatic systems is further underlined by the fact that selenium-respiring organisms can also completely reduce selenate in the presence of a high molar excess of the structural analog sulfate (Lenz et al. 2008b). Since so specific for selenate, selenium-respiring organisms may offer an alternative to the currently applied two-step process. However, bioaugmentation by simple addition of cell cultures is typically limited by wash-out and outcompetition of the inoculated culture by the endogenous microorganisms (El Fantroussi and Agathos 2005). Immobilization in gel has been suggested to counteract these limitations, yet the performance has not been tested in continuous experiments so far (Morita et al. 2007; Tucker et al. 1998). Sulfurospirillum barnesii is a particularly promising inoculum as it can respire a variety of substrates (including both selenium oxyanions, nitrate, and nitrite), produces elemental selenium as end-product of selenium respiration, and is non-pathogenic (Oremland et al. 1999; Stolz et al. 1999).

In order to assess the performance of bioreactors in continuous operation, the inoculation with immobilized selenium-respiring microorganisms was investigated in the present study. To validate the applicability of gel immobilization under microbial competition, one Upflow Anaerobic Sludge Bed (UASB) reactor was inoculated with both immobilized bacteria and anaerobic granular sludge. The selenate removal efficiency was evaluated in comparison to a non-bioaugmented UASB reactor. The chemical composition of selenium bioprecipitates was investigated by SEM-EDX. In addition, denaturing gradient gel electrophoresis (DGGE) and nucleotide sequencing were used to evaluate the immobilization success.

\section{Materials and methods}

\section{Source of biomass}

S. barnesii (strain 10660) was obtained from the German Collection of Microorganisms and Cell Cultures (DSMZ, Braunschweig, Germany). Anaerobic granular sludge originated from a full-scale UASB reactor treating paper mill wastewater (Industriewater Eerbeek B.V., Eerbeek, The Netherlands).

\section{Media}

For S. barnesii cell immobilization experiments, bacterial cells were pregrown in medium prepared according to DSMZ, containing nitrate as electron acceptor and lactate as electron donor $(20 \mathrm{mM}$ each, see Electronic supplementary material for complete medium composition). During bioreactor operation, oxygen-free synthetic wastewater containing macronutrients, micronutrients (Lenz et al. 2006), and a vitamin solution (according to DMSZ medium for $S$. barnesii) was used. The medium was buffered at $\mathrm{pH}=7.0$ ( \pm 0.1 ) using a $40 \mathrm{mM}$ phosphate buffer.

Biomass immobilization

Cells were harvested in the exponential growth phase by centrifugation of $20 \mathrm{~mL}$ cell suspension at $11,000 \times \mathrm{g}$ for 20 min (IEC CL31R Multispeed Centrifuge, Thermo Scientific, Breda, The Netherlands). The pellet was resuspended in $500 \mu \mathrm{L}$ of $S$. barnesii medium, and $125 \mu \mathrm{L}$ of 
this suspension was added to $50 \mathrm{~mL}$ of polymerizing gel and stirred gently. Gelling conditions were used according to Tucker et al. (1998), but using different ratios of $N, N^{\prime}$ methylenebisacrylamide (MBAA) and acrylamide (AA). The gel was poured into sterile plastic beds of $8 \mathrm{~cm} \times 8 \mathrm{~cm} \times$ $4 \mathrm{~mm}$. After hardening, the gel was cut with a sterile scalpel into cubes of $4 \times 4 \times 4 \mathrm{~mm}$. All immobilization steps were conducted under $\mathrm{N}_{2}$ atmosphere in a glove box.

\section{Characterization of the $S$. barnesii cubes}

The effect of the gelling conditions on the fracture stress of the gel cubes was determined by the strength needed to burst a $1-\mathrm{cm}^{3}$ gel cube at the brittle point, measured by a penetrometer (Overload Dynamics S900, Overload Dynamics, Schiedam, The Netherlands).

The influence of the gel composition on the selenate reduction efficiency was studied in $125-\mathrm{mL}$ batch bottles containing ten gel cubes with immobilized $S$. barnesii cells (total of $16.1 \mu \mathrm{g}$ biomass dry weight) in $50 \mathrm{~mL}$ of synthetic wastewater. Selenate was added from a concentrated stock solution to a final concentration of $100 \mu \mathrm{M}$. The batch bottles were subsequently flushed with a sterile stream of $\mathrm{N}_{2}$ and incubated at $30^{\circ} \mathrm{C}$ on a horizontal shaker at $120 \mathrm{rpm}$.

\section{Continuous bioreactor set-up}

The bioreactors ( $0.46 \mathrm{~L}$ working volume) were operated under mesophilic conditions $\left(30 \pm 1^{\circ} \mathrm{C}\right)$ and a hydraulic retention time (HRT) of $6 \mathrm{~h}$ as described previously (Lenz et al. 2008b). To avoid nitrate, selenate, or sulfate bioconversion in the storage vessels, influents were composed of three different streams, fed in the same ratios to the reactor: (1) solution of selenate, sulfate, nitrate, macro-/micronutrients, and vitamins, (2) lactic acid dissolved in phosphate buffer, and (3) dilution water.

\section{Bioreactor operation}

Three bioreactors (R1-R3) were inoculated as follows: R1 received 25 gel cubes (1:30, MBAA/AA). R2 was operated as a regular UASB reactor (Lenz et al. 2008b) and inoculated with $100 \mathrm{~g}$ wet weight [37.4×g volatile suspended solids (VSS) $\left.{ }^{-1} \mathrm{~L}^{-1}\right]$ of anaerobic granular sludge. R3 received both cubes and sludge in the same quantities used to inoculate R1 and R2, respectively.

Lactate was used as sole electron donor at an influent concentration of $13 \mathrm{mM}$ (12 mol of electrons per mole lactate), resulting in an organic loading rate of $5 \mathrm{~g} \mathrm{COD} \times$ $\mathrm{L}^{-1}$ day ${ }^{-1}$, corresponding to a specific organic loading rate of $134 \mathrm{mg} \mathrm{COD} \times \mathrm{gVSS}^{-1}$ day $^{-1}$. Nitrate was supplemented to the reactors as main electron acceptor at an influent concentration of $15 \mathrm{mM}$ ( $5 \mathrm{~mol}$ of electrons per mole of nitrate reduced) in period I (days 0 to 24) and period III (days 43 to 58), whereas no nitrate was supplied in period II (days 25 to 42). Sulfate and selenate (accepting 8 and 6 mol of electrons during reduction to sulfide and elemental selenium, respectively) were supplemented at influent concentrations of $2 \mathrm{mM}$ and $10 \mu \mathrm{M}$, respectively, during the whole reactor operation.

\section{Microscopy}

For SEM, samples were fixed for $1 \mathrm{~h}$ in an aqueous glutaraldehyde solution $(2.5 \%)$, rinsed with water, and dried either in a $\mathrm{N}_{2}$ stream or in a series of ethanol (Lenz et al. 2008b). Samples were then fixed to a brass sample holder with carbon adhesive tabs (Electron Microscopy Sciences, Hatfield, USA) and coated with $5 \mathrm{~nm}$ platinum by magnetron sputtering. Specimens were analyzed with a field emission scanning electron microscope (JEOL $6300 \mathrm{~F}$, Tokyo, Japan). EDX (INCA energy, Oxford Instruments Analytical, High Wycombe, England) was performed at a voltage of $15 \mathrm{kV}$ and a working distance of $15 \mathrm{~mm}$.

Microbial community structure analysis

DNA extraction and PCR-amplification of $16 S$ rRNA genes

Total genomic DNA was extracted from the R2 and R3 biomass and an unfiltered effluent sample of R1 obtained at the conclusion of the trial (day 58) using a DNeasy ${ }^{\circledR}$ Plant Mini Kit (Qiagen, Germany). Extracted DNA was visualized by UV excitation as previously described (Enright et al. 2007). Partial bacterial 16S rRNA genes were amplified with the forward primer $341 \mathrm{~F}$ and reverse primer $517 \mathrm{R}$, a 40-base pair GC-clamp was attached to the 5' terminus of the forward primer (Muyzer et al. 1993). The PCR reaction mixture and PCR conditions are described in the Electronic supplementary material.

\section{Analysis of PCR products by DGGE}

Polyacrylamide gels were prepared with denaturing gradients ranging from $30 \%$ to $70 \%$ denaturant $(100 \%$ denaturant $=7 \mathrm{M}$ urea $+40 \%$ formamide), and loaded with $20 \mu \mathrm{L}$ of the respective GC-clamped PCR products (Muyzer et al. 1993). Gels were run at $65^{\circ} \mathrm{C}$ and $75 \mathrm{~V}$ for $16 \mathrm{~h}$. Following this, gels were stained/destained (10 min, respectively) and photographed on a UV transillumination table. Bands of interest were excised from the DGGE gels using a sterile scalpel blade, suspended in $50 \mu \mathrm{L}$ of sterile water, and stored at room temperature for $6 \mathrm{~h}$ to facilitate the elution of DNA. Both the PCR and GC-clamped PCR product analysis was repeated up to five consecutive times, in order to insure the presence of a single isolated band. 
Sequencing of $16 S$ rRNA gene fragments and phylogenetic analysis

PCRs were performed under the conditions described above, but without GC clamps attached to the forward primers. Sequences were determined using a capillary sequencer (MWG Biotech, Germany) and aligned with 16S rRNA gene sequences retrieved from the Ribosomal Database Project (RDP; Maidak et al. 1996). Sequences were then aligned to previously deposited sequences, downloaded from the RDP website, using ClustalX (Thompson et al. 1997). The phylogenetic inference package Paup* $4.0 \mathrm{~b} 8$ was used for all phylogenetic analysis (Swofford 2001), using the Kimura-2 parameter correction (Kimura 1980; Saitou and Nei 1987) and partial bacterial 16S rRNA gene sequences deposited in the GenBank database (accession numbers in Electronic supplementary material).

Analytical techniques

Selenate, selenite, nitrate, nitrite, and sulfate were determined by ion chromatography as described previously (Lenz et al. 2006). The dissolved sulfide concentration of the effluent was determined colorimetrically (Dr. Lange, LYW653, Germany). Total dissolved selenium $\left(\mathrm{Se}_{\mathrm{dis}}\right)$ was determined by inductively coupled plasma-optical emission spectroscopy (detection limit $10 \mu \mathrm{g} \mathrm{Se} \times \mathrm{L}^{-1}$ ) after filtration using a $0.45-\mu \mathrm{m}$ pore size syringe filter (Whatman, Hertogenbosch, The Netherlands). Volatile fatty acids (VFAs) and biogas composition were determined by gas chromatography (Weijma et al. 2000).

\section{Results}

Selenate removal in batch assays

Gels containing MBAA/AA in a ratio of 1:30 had the highest fracture stress (Table 1). Higher AA concentrations

Table 1 Influence of different $N, N^{\prime}$-methylenebisacrylamide/acrylamide compositions on gel strength and selenate reduction rates by immobilized S. barnesii cells

\begin{tabular}{lll}
\hline $\begin{array}{l}\text { Ratio } N, N^{\prime}- \\
\text { methylenebisacrylamide/ } \\
\text { acrylamide }\end{array}$ & $\begin{array}{l}\text { Fracture stress } \\
{\left[\mathrm{N} / \mathrm{cm}^{2}\right]}\end{array}$ & $\begin{array}{l}\text { Selenate removal } \\
{\left[\mu \mathrm{g} \mathrm{Se} \times \mathrm{g} \mathrm{dw}^{-1} \mathrm{~h}^{-1}\right]}\end{array}$ \\
\hline $1: 5$ & - & - \\
$1: 10^{\mathrm{a}}$ & $6.0 \pm 2.3$ & - \\
$1: 20$ & $23.5 \pm 4.4$ & $60.5 \pm 0.4$ \\
$1: 30$ & $39.3 \pm 10.9$ & $69.1 \pm 3.9$ \\
$1: 40$ & $9.3 \pm 3.0$ & $49.0 \pm 7.1$ \\
\hline
\end{tabular}

${ }^{\text {a }}$ Gel needed 15 min to harden resulted in hard, shattering gels, whereas lower concentrations caused incomplete gelling. Furthermore, the selenate removal rates in the 1:30 MBAA/AA gels were $14 \%$ and $41 \%$ higher compared to gels with a ratio of $1: 20$ and $1: 40$, respectively. Consequently, the 1:30 gel cubes were used to inoculate R1 and R3.

Start-up of the UASB reactors

During the start-up (period I), low selenate and $\mathrm{Se}_{\mathrm{dis}}$ removal efficiencies were observed in all three reactors (Fig. 1a-c). R3 showed the highest selenate reduction efficiency of the three reactors at the end of period I $(20 \%$ on day22). Although selenate was removed by the bioreactor, total selenium analysis showed a wash-out of undetermined selenium species with the effluent $(4 \%$ of the influent selenium).

Nitrate was removed completely by R1 and R2 within 8 and 6 days of operation, respectively, whereas a complete removal was achieved in R3 already 20 and 12 HRTs earlier (Fig. 2a-c). In R2, complete nitrate removal was not sustained, and nitrate followed nitrite accumulation in the effluent after 13 days of operation (Fig. 2b). Sulfate was not removed in any of the reactors in period I (Fig. 2d-f).

The COD removal efficiency exceeded $82 \%$ and $87 \%$ throughout most of period I in R1 and R3, respectively, after a start-up period of approximately 6 days (Fig. $2 \mathrm{~g}$ and i). When nitrate removal was low in R2 $(9.2 \mathrm{mM}$ nitrate $+0.7 \mathrm{mM}$ nitrite in effluent, Fig. 2b), a slight accumulation of acetate $(2.7 \mathrm{mM})$ was observed, resulting in a reduced COD removal efficiency of $54 \%$.

Effect of bioaugmentation on reactor performance in the absence of nitrate

Upon omitting nitrate from the feed (period II), R1 and $\mathrm{R} 3$ reacted with an immediate increase in both selenate and dissolved selenium $\left(\mathrm{Se}_{\mathrm{dis}}\right)$ removal efficiencies (Fig. 1a and c). Comparative selenium removal efficiencies were achieved in R2 only after a delay of 5 days ( 20 HRT; Fig. 1b).

The $\mathrm{Se}_{\mathrm{dis}}$ removal efficiency was lower than the selenate removal efficiency in all three reactors with maximal differences of $37 \%, 34 \%$, and $43 \%$ in $\mathrm{R} 1$ to $\mathrm{R} 3$, respectively. Toward the end of period II, the difference became smaller in all three reactors. The lowest $\mathrm{Se}_{\mathrm{dis}}$ effluent concentration was $39 \mu \mathrm{g} \mathrm{Se} \times \mathrm{L}^{-1}$ in R1, while R2 and R3 reduced $\mathrm{Se}_{\text {dis }}$ less efficiently (120 and $174 \mu \mathrm{g} \mathrm{Se} \times$ $\mathrm{L}^{-1}$, respectively).

Immediately upon the transition from period I to II, the sulfate removal efficiency increased in the bioaugmented reactors (R1 and R3, Fig. 2d and f), while this occurred in 

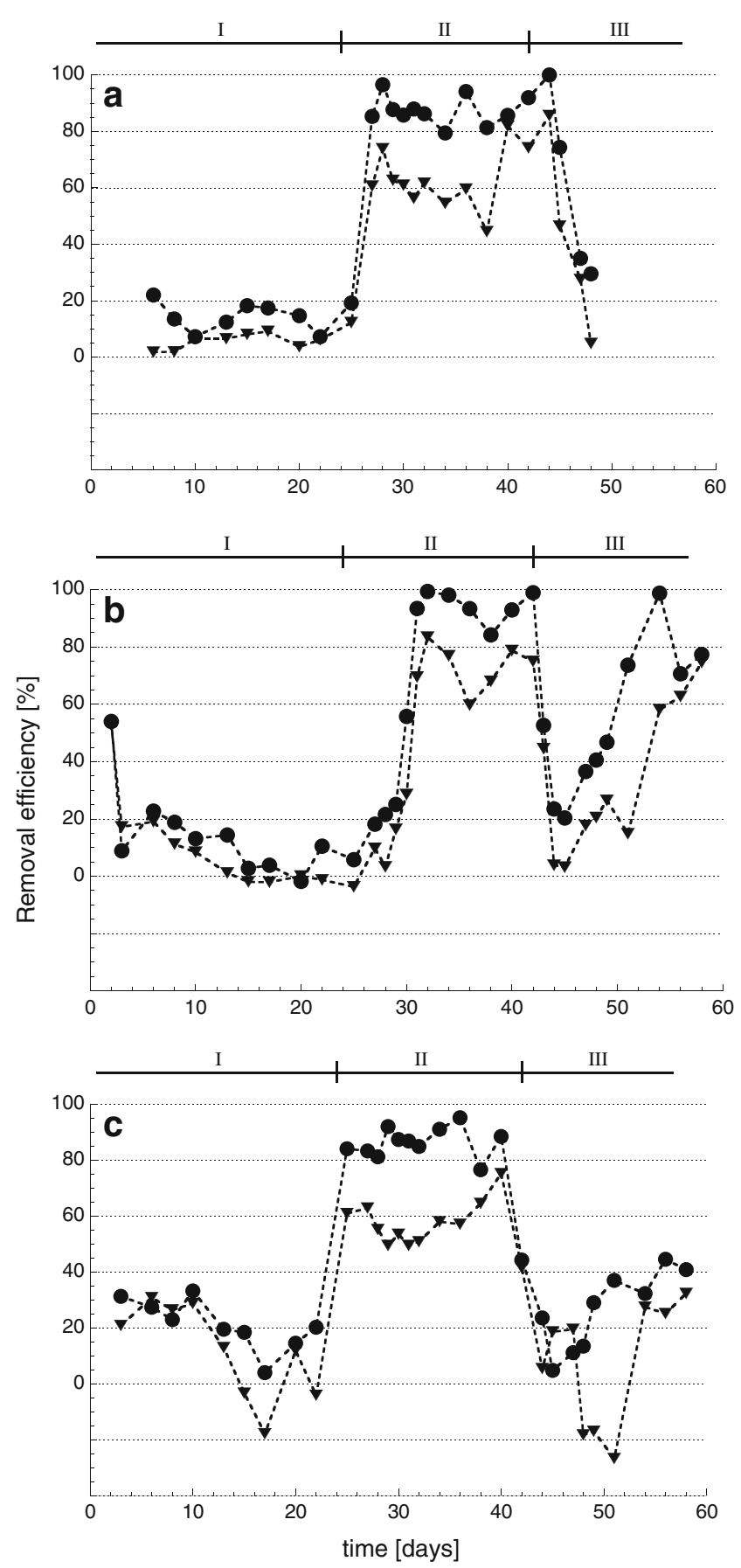

Fig. 1 Reactor performance of R1 (a), R2 (b), and R3(c). $=\mathbf{- O}=$ selenate and 0 dissolved selenium removed [\%] from the liquid phase. Roman numerals mark different operational periods with $(I, I I I)$ and without $(I I)$ nitrate

R2 with a delay of more than 8 days of operation (32 HRT; Fig. 2e). The highest amounts of dissolved sulfide accumulated in R3 (1.2 mM, Fig. 2f), while $41 \%$ less dissolved sulfide was formed in R1. COD removal efficiencies were generally low in period II compared to period I and III (Fig. $2 \mathrm{~g}$ to h). Propionate was the main VFA accumulating in the R2 and R3 effluent, while propionate and acetate accumulated in the effluent of R1 (Fig. 2g).

Effect of bioaugmentation on reactor performance in the presence of nitrate

When resuming the nitrate feed (period III), the selenate and $\mathrm{Se}_{\text {dis }}$ removal efficiency immediately decreased in R2 and R3 (Fig. $1 \mathrm{~b}$ and c), whereas this decrease occurred with a delay of 2 days of operation (8 HRT) in R1. Upon termination of the reactor operation, an almost complete selenate removal was achieved in R2 (<97\%), while R3 removed only 56\% selenate. Due to a blockage of the nutrient line, only lactate and dilution water was fed to R1 subsequently to day 51 . Thus, selenate and $\mathrm{Se}_{\mathrm{dis}}$ removal efficiencies could not be determined until the end of period III.

Again, $\mathrm{Se}_{\mathrm{dis}}$ was less efficiently removed compared to selenate, with a difference of up to $59 \%$ (R2) and $64 \%$ (R3). $\mathrm{Se}_{\mathrm{dis}}$ even washed out of R3 in period III (Fig. 1c). The application of a $0.1 \mu \mathrm{m}$ filter subsequently to filtration with a pore size of $0.45 \mu \mathrm{m}$ increased the $\mathrm{Se}_{\mathrm{dis}}$ removal efficiency in R2 by $11 \%$ to $48 \%$ (period III, data not shown).

Immediately upon resuming the nitrate feed, high nitrate/ nitrite removal efficiencies were achieved that exceeded $91 \%$ in both R2 and R3 (Fig. 2b and c), while sulfate removal efficiencies dropped upon transition to period III (Fig. 2d to f). The COD removal efficiency was high $(>82 \%)$ throughout the whole period III in both R2 and R3 (Fig. $2 \mathrm{~h}$ and i). R1 accumulated both acetate and propionate in the effluent, resulting in no net-COD removal upon the end of the reactor operation (Fig. 2g).

\section{Characterization of the selenium precipitate}

During batch incubation of immobilized $S$. barnesii with selenate, a red-colored precipitate was first observed within the cubes and subsequently in the whole batch medium (Fig. 3a). SEM analysis of the gel cubes following the batch experiments showed that the gel cube surface was entirely covered with selenium precipitates (Fig. $3 b$ ), whereas the inside of the cube contained fewer, but larger selenium precipitates (Fig. 3c). The EDX maps show these consisted mainly of selenium, with smaller contributions of sulfur (scan S1, Fig. 3c and d).

The gel cubes obtained from R1 upon termination of the reactor operation were entirely crusted by calcium and phosphorous containing precipitates, as demonstrated by the EDX surface scan (spectrum S2, Fig. 3e and h). The cross-sections showed flower-like structures up to 70 $\mu \mathrm{m}$ from the edge of the cube (Fig. 3f and g), mainly consisting of calcium and phosphorous (spectrum S3, Fig. 3h). 

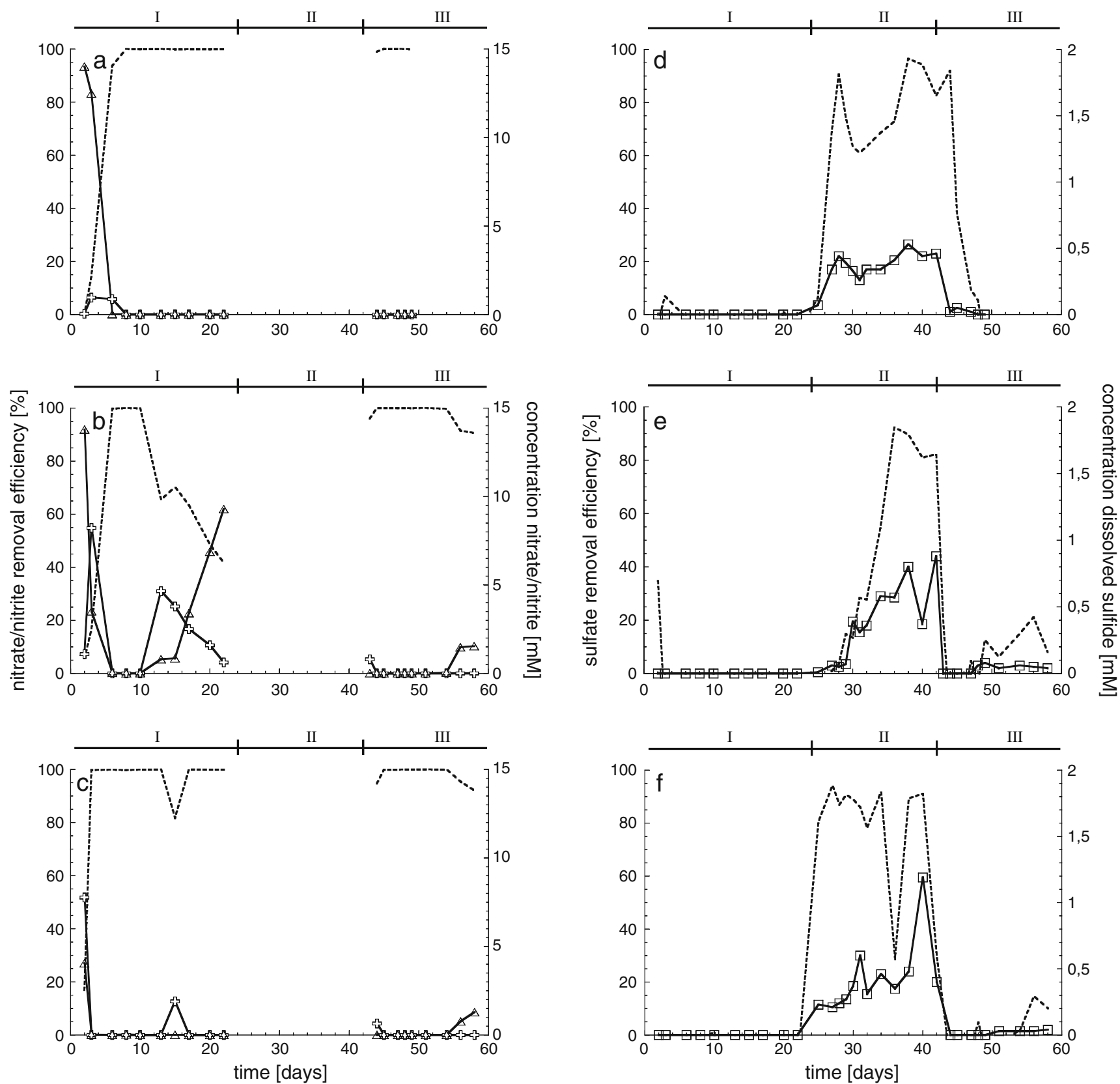

Fig. 2 Reactor performance of R1 (a, d, g), R2 (b, e, h), and R3(c, f, i). Removal efficiency $(\boldsymbol{\square} \boldsymbol{\square} \boldsymbol{\square})[\%]$ from liquid phase on primary axis;

nitrite,

$\square$

Biomass characterization and microbial community structure

The sludge bed volume of R2 and R3 more than doubled ( $220 \mathrm{~mL}$ final volume), and a color change from dark black to light gray with slime embedding the granules was observed during the reactor operation, but the granular character of the sludge remained. Selenium accumulated in the sludge granules (and the embedding slime) of R2 and R3 up to 1067 (R2) and $1194 \mu \mathrm{g} \mathrm{Se} \times$ $\mathrm{gVSS}^{-1}$, respectively. In R1, low amounts of white flocks

dissolved sulfide, acetate, and propionate concentration on secondary $y$-axis. Roman numerals mark different operational periods with $(I, I I I)$ and without $(I I)$ nitrate

formed that were loosely deposited on top of the cube bed.

Sulfurospirillum-like species were detected in the R1 unfiltered effluent and the R2 and R3 biomass samples obtained at the trial conclusion (B4-FJ499345, Figs. 4 and 5). Furthermore, a selenium-reducing organism (selenatereducing bacterium TSA) was also detected in the R2 and R3 biomass samples (B20-FJ499361, Figs. 4 and 5). In addition, members of the closely related genus (i.e., Klebsiella) previously shown to reduce selenate were indicated in the samples of R1 (B5-FJ499346, Figs. 4 and 5). 

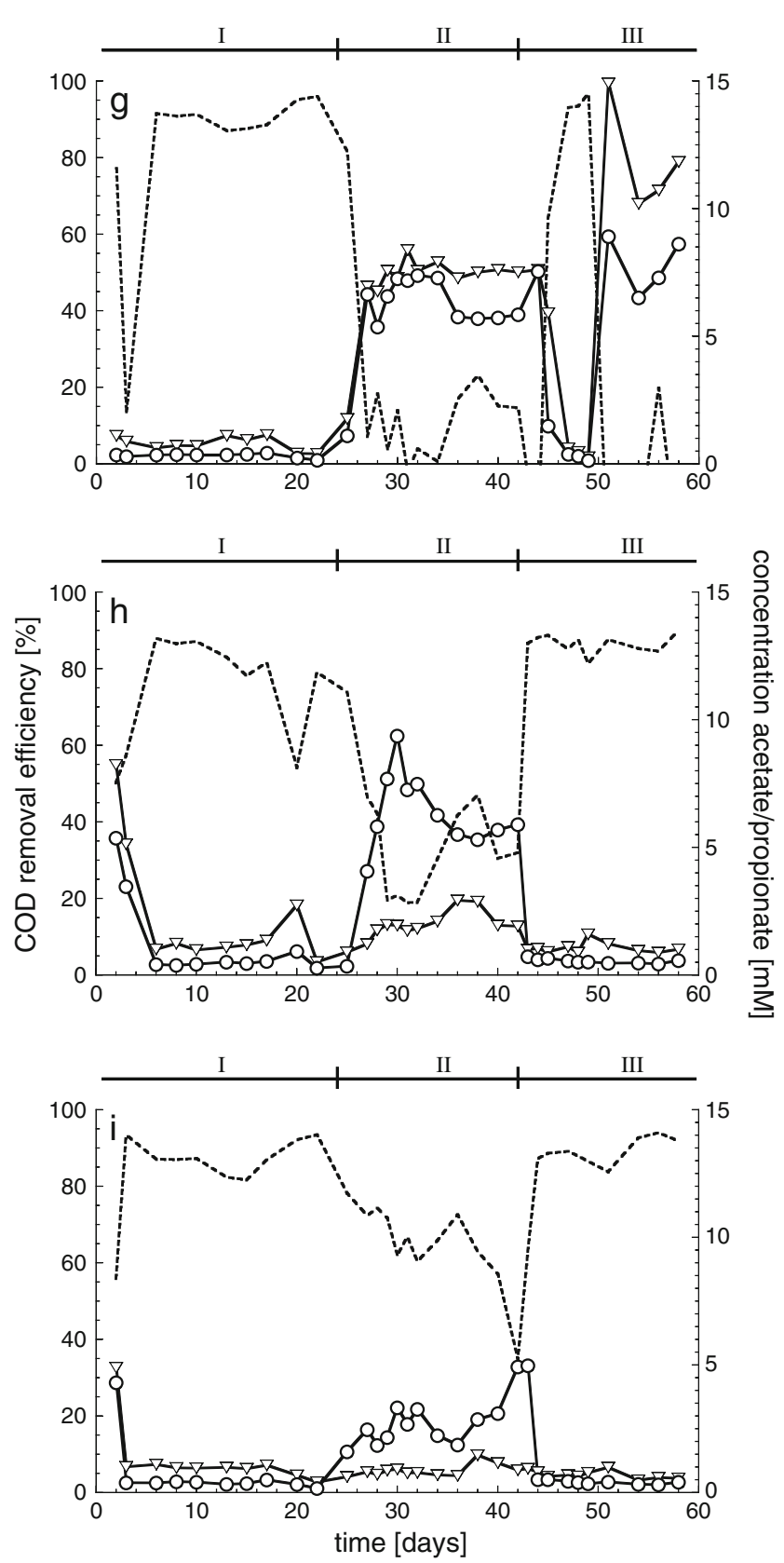

Fig. 2 (continued)

\section{Discussion}

Whole-cell immobilization and bioaugmentation of $S$.

barnesii in bioreactors

This study shows that gel immobilization can be used to immobilize both microorganisms and their precipitation products (Fig. 3b and c), i.e. elemental selenium, and sustain microbial reductive activity under long term (58 days) reactor operation (Fig. 1a). DGGE and sequencing of the excised bands demonstrated that biomass was seeded to the reactor liquid and the sludge granules as a Sulfurospirillum species were found in the effluent of R1 and the sludge of R3 after 58 days of operation (B4-FJ499345, Fig. 5). Thus, immobilization in gels is promising for applications requiring a continuous release of biomass (Boon et al. 2002), superseding wash-out or out-competition in bioaugmentation. For example, bioaugmentation of UASB reactors with sulfate reducers, so far unsuccessful due to the use of suspended cultures as bioaugmentation inoculum (Vallero et al. 2004), might be a future application. Immobilization was achieved in non-biodegradable polyacrylamide gels (Leenen et al. 1996), which is important when considering full-scale applications.

Members of the genus Klebsiella (Klebsiella oxytoca, B5-FJ499346, Fig. 5) have been described to reduce selenate (Zhang et al. 2008) and might contribute to the selenate removal in R1. Proliferation of further microorganisms (additional bands in Fig. 4) can also explain sulfate reduction in R1, as $S$. barnesii is not capable to use sulfate as terminal electron acceptor.

Although nitrate/nitrite concentrations were reduced to $<1 \mu \mathrm{M}$, selenate was not reduced at the start-up of the reactor (Fig. 1a). When incubating $S$. barnesii under high excess of nitrate $(5 \mathrm{mM})$ to selenate $(50 \mu \mathrm{M})$ with lactate as electron donor, Oremland et al. (1999) observed selenate reduction at a strongly decreased rate (factor $>48$ ) compared to incubations without nitrate. Consequently, the incomplete removal efficiencies observed in period I of R1 and R3 can be explained by a kinetic limitation, i.e., the reactor medium is continuously replaced, resulting in a hydraulic retention too short to completely remove selenate. Omitting nitrate from the feed consequently increases selenate reduction activity (during transition to period II). The increase in selenate-reducing activity can be determined as $0.097(\mathrm{R} 1)$ and $0.099 \mu \mathrm{M}$ selenate $\times \mu \mathrm{g} S$. barne$s i i_{\text {initial }}{ }^{-1}$ day $^{-2}$ (R3) by fitting the increase in selenate removal efficiency linearly.

During the first 20 (R1) and 22 days (R2+3) of reactor operation, no sulfate reduction was observed, thus no sulfide was available to chemically precipitate biogenically formed selenite (Hockin and Gadd 2003). Consequently, selenate was completely reduced to elemental selenium in period I. During later reactor operation, biogenically formed sulfide was present in all three reactors in molar excess to selenate (Fig. 2), which might have precipitated potentially formed selenite completely.

The fact that $\mathrm{Se}_{\text {dis }}$ and selenate removal efficiencies in $\mathrm{R} 3$ were lower compared to R2 in period III can be due to sulfide toxicity (Lenz et al. 2008b) as dissolved sulfide concentrations had build up to higher levels $(1.2 \mathrm{mM})$ in period II. 
Fig. 3 a Immobilized S. barnesii cells during production of elemental red selenium $(0,48$, and $168 \mathrm{~h}$ ) and SEM pictures of batch cubes (b, c) with EDX mapping (d) of selected area (S1) containing precipitates. Surface (e) and cross-section $(\mathbf{f}, \mathbf{g})$ of a cube sampled after 58 days of reactor operation with (h) surface scan of $S 2$ and of precipitate within the cube
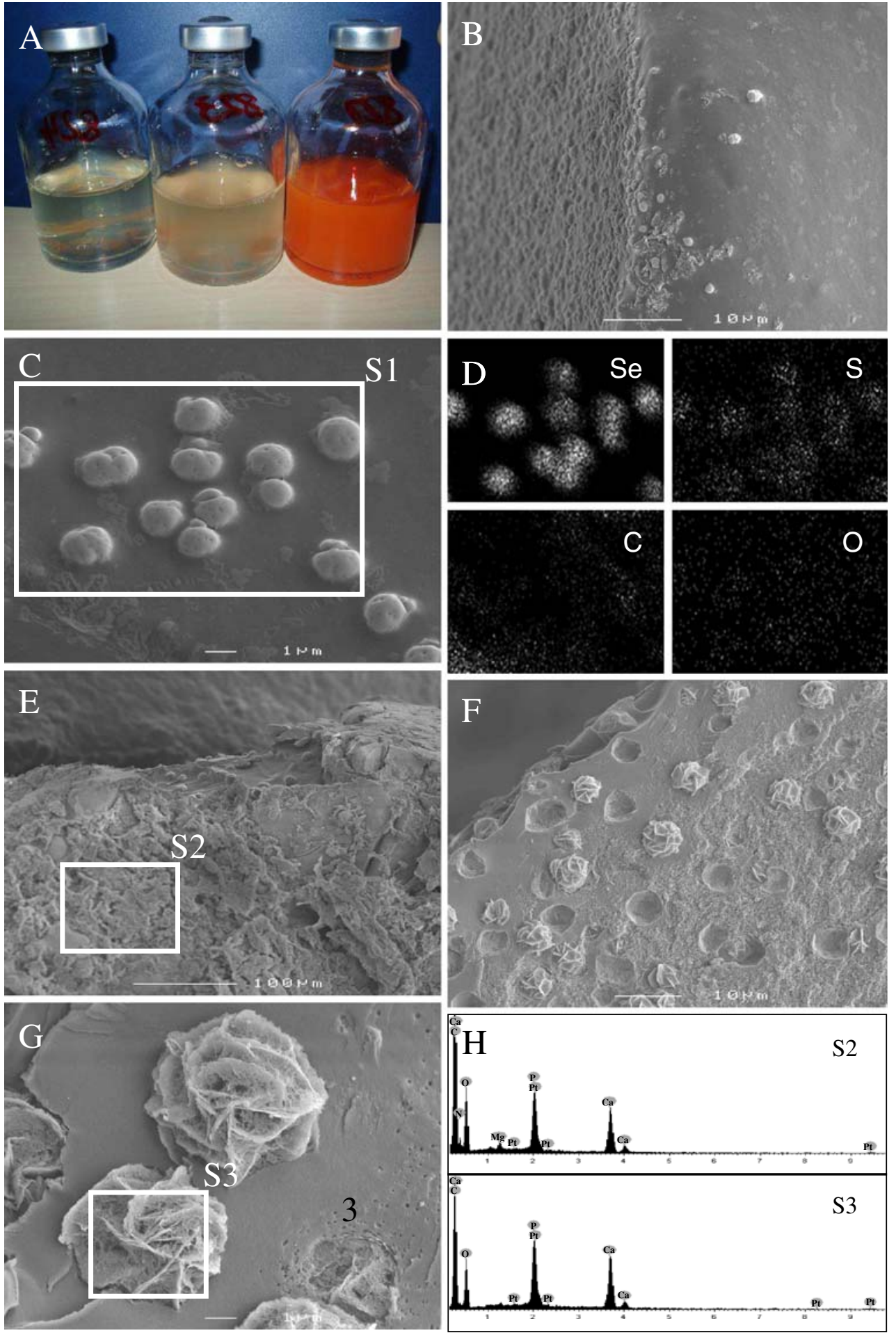

Selenate removal in denitrifying UASB reactors

This study shows that UASB reactors can reduce selenate under completely denitrifying conditions (period III, Fig. 1b) due to the proliferation of a selenium-respiring specialist (B20-FJ499361, Fig. 5). Thus, such reactors can be applied as an alternative to a two-step denitrifyingselenate-reducing process (Green et al. 2003) or the bioaugmentation with selenium-respiring organisms. Proliferation of a selenium-respiring population in anaerobic granular sludge of the same origin was also observed when it was operated under methanogenic conditions (Lenz et al. 
Fig. 4 PCR-DGGE fingerprints (30\% denaturing agent on left, $70 \%$ right $)$ of the effluent sample $(R I)$ and the bioreactor sludge samples $(R 2$ and $R 3)$. Ribotype names B1-B20 can be found in supplementary information

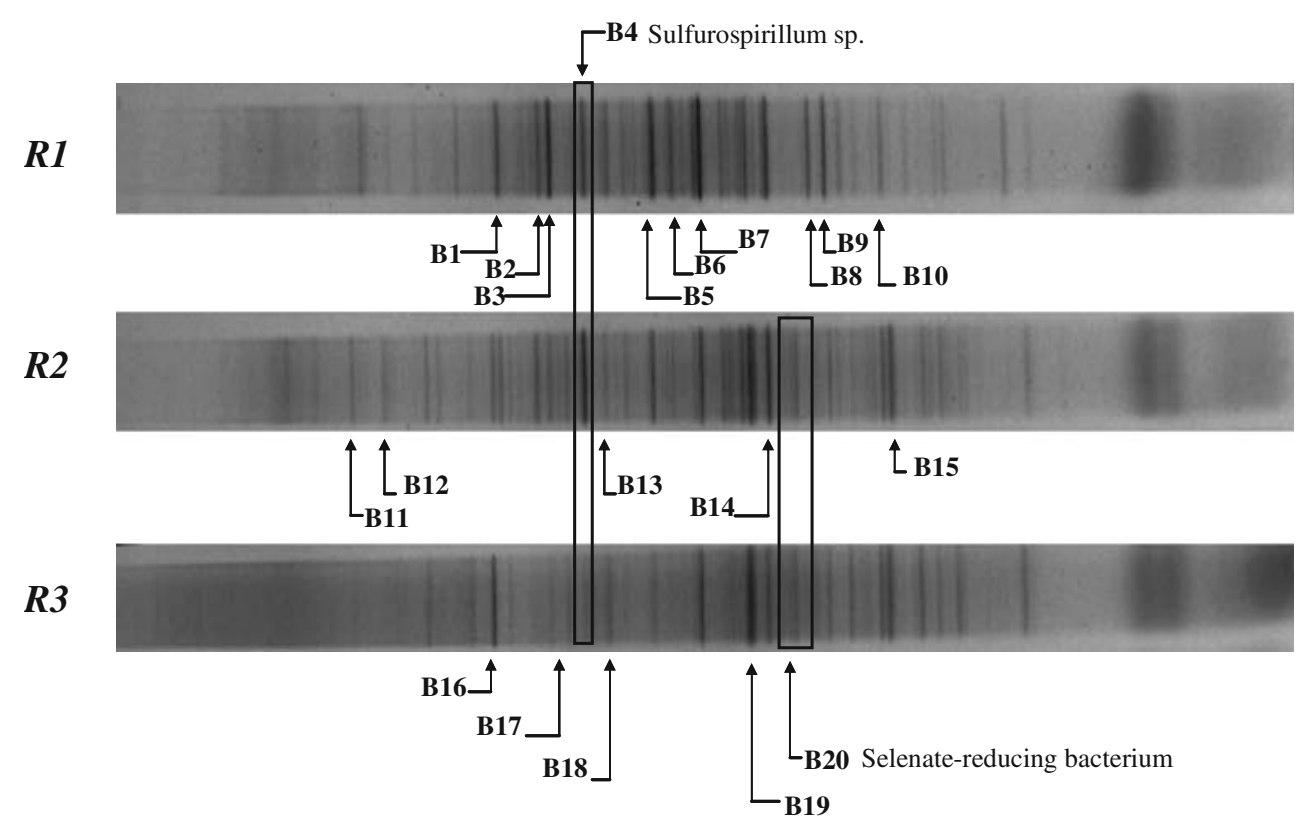

2008 b), underlining the versatility of this inoculum. The matched selenate-reducing bacterium TSA (AB018593) is closely related to the genus Citrobacter that has been applied to reduce selenate from drainage waters containing

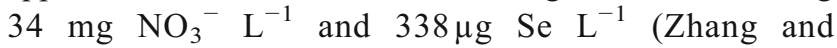
Frankenberger 2006). Surprisingly, it is a close relative to the clone from R1 resembling to the Klebsiella species (B5FJ499346; Fig. 5), although generally, dissmilatory selenate reducers are phylogenetically divers (Stolz et al. 2006). It is indicated that the selenate-reducing bacterium TSA (AB018593) is originating from the inoculum sludge, as it was matched in R2 and R3, only (Fig. 5). Interestingly, a Sulfurospirillum species also proliferated in the nonbioaugmented reactor.

\section{Precipitate characterization}

This study shows that the particle size of the bioprecipitates formed within the gel cubes is more than a factor 5 bigger $(\leq 2 \mu \mathrm{m}$, Fig. $3 \mathrm{c})$ compared to previous studies (Lenz et al. 2008a; Oremland et al. 2004) using suspended cultures. As not subject to sheer forces, selenium precipitates formed by a membrane bound enzyme (Oremland et al. 1999) are not sloughed from the cell, and larger particle sizes can thus develop due to the cell immobilization in the gel. This effect might be used to select for larger bioprecipitates in certain applications (i.e., metal precipitation for recovery). Precipitation within the gel separates part of the selenium from the water phase; thus, it does not leave the treatment plant with the effluent, preventing reoxidation in the environment (Zhang et al. 2004). As the gel cubes did not float under the applied superficial upflow velocity, they can be easily recovered by settling for potential selenium re-use (Lenz and Lens 2009). However, technical processes for the re-use need to be developed. Potentially, selenium could be recovered by heating of the gel cubes since polyacrylamide has a lower melting point compared to elemental selenium $\left(102^{\circ} \mathrm{C}\right.$ and $217^{\circ} \mathrm{C}$, respectively).

In contrast to previous studies (Oremland et al. 2004), the precipitates consisted of selenium-sulfur mixtures (Fig. 3d), with sulfur either originating from sulfide used as reductant or sulfate present in the $S$. barnesii batch medium (see Electronic supplementary material). As sulfate is present in many drainage waters (Presser 1994) and thus biogenic sulfide can be formed, this will lower the selenium purity when considering re-use. The cementation of the cubes by inorganic precipitates from the feed medium (here calcium-phosphorous precipitates, Fig. $3 f$ and g) might limit substrate transport to the organisms (van Langerak et al. 2000) during long time ( $>58$ days) reactor operation.

Implications for practical applications

This study shows that regular UASB reactors can be applied to treat selenate-rich wastewaters under completely denitrifying conditions. However, in acute contamination situations, e.g., in case of spillages of ore processing waste (Taggart et al. 2006), the application of bioaugmented reactors can be advantageous due to the long start-up time required in regular UASB reactors (Lenz et al. 2008a; Lenz et al. 2008b). However, it is necessary to pre-activate $S$. barnesii for such bioaugmentative applications to induce selenate reduction. This problem can potentially be avoided if selenium-respiring specialists that are unaffected by nitrate are bioaugmented to an already denitrifying sludge. 


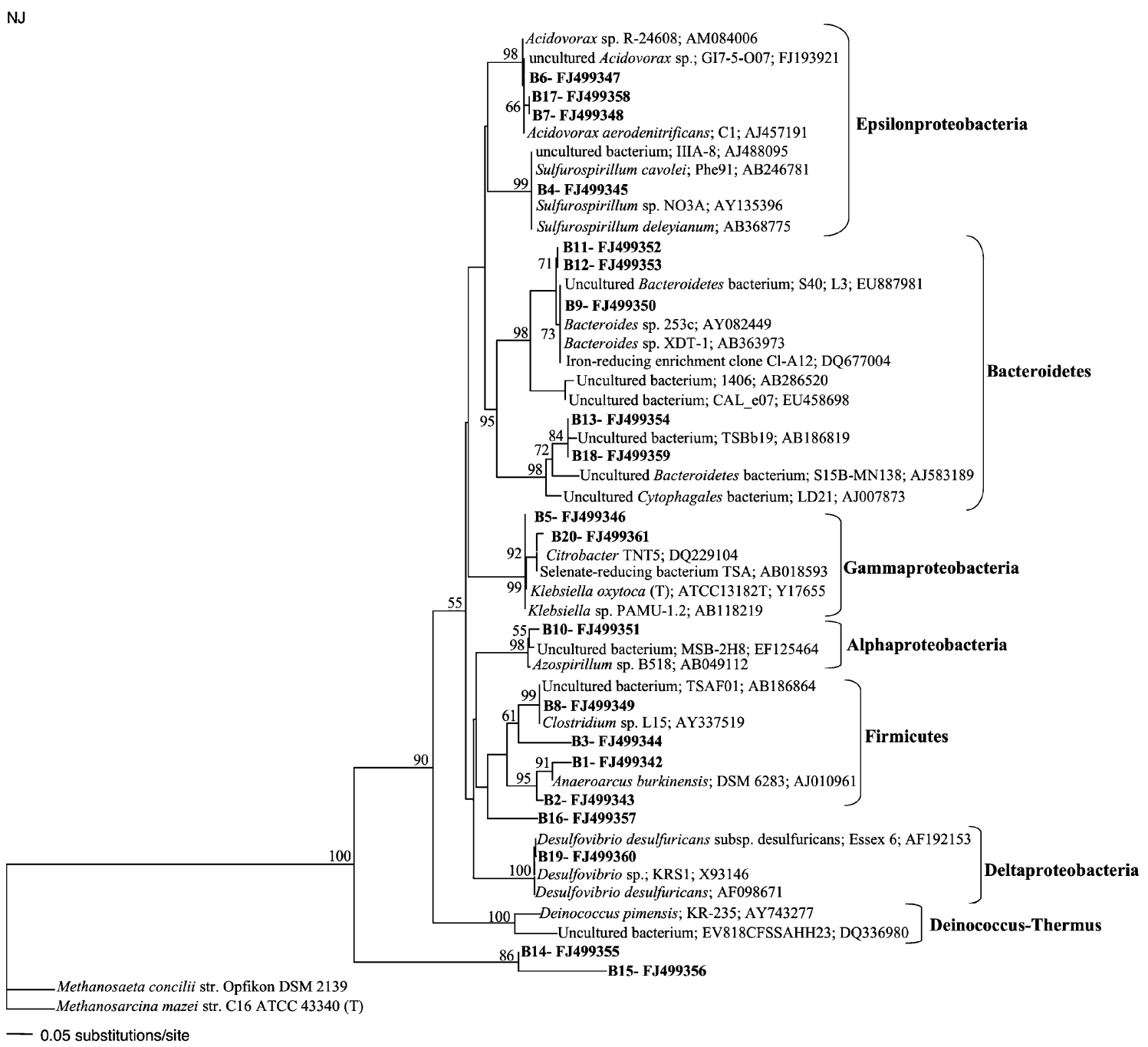

Fig. 5 Phylogeny of bacterial DGGE sequences obtained from R2 and R3 biomass and an unfiltered effluent sample of R1 (obtained at the conclusion of the trial-day58) based on the Kimura- 2 model and the neighbor-joining method. Bootstrap replicates (out of a total of
100 replicate samplings) that supported the branching order are shown at the relevant nodes. The scale bar represents five nucleotide substitutions per 100 sequence positions. GenBank accession numbers are provided for sequenced DGGE bands and reference sequences
The effluent $\mathrm{Se}_{\mathrm{dis}}$ concentration of $39 \mu \mathrm{g} \mathrm{Se} \times \mathrm{L}^{-1}$ achieved in R1 meets the current water quality criterion for salt waters $\left(71 \mu \mathrm{g} \mathrm{Se} \times \mathrm{L}^{-1}\right)$ set by the Unites States Environmental Protection Agency (USEPA 2002). As filtration could further reduce $\mathrm{Se}_{\mathrm{dis}}$ concentrations by removing selenium fines (between 450 and $100 \mathrm{~nm}$ particle size) from the R2 effluent, dissolved air flotation might be dispensable in practice, and slow sand filtration could be used as sole post-treatment of the effluent prior to emission [instead of the combination of both currently applied (Green et al. 2003)]. Furthermore, the hydraulic retention times applied here are much shorter in contrast to the algalbacterial system ( $6 \mathrm{~h}$ versus 10-16 days; Green et al. 2003). It is important to note that no selenite was detected at any sample of R1, R2, or R3 (detection limit $24 \mu \mathrm{g} \mathrm{Se} \times \mathrm{L}^{-1}$ ) as selenite is more toxic to aquatic invertebrates and fish than selenate (Hamilton 2004). If formed, it is further reduced to elemental selenium by nitrite reductases (Oremland et al. 1999) or precipitated chemically with biogenic sulfide (Hockin and Gadd 2003) formed during reactor operation.

If a classical UASB or hybrid system (UASB + immobilization gel cubes) is applied, an additional requirement of electron donor has to be taken into account to sustain the granular structure of the sludge (Gonzalez-Gil et al. 2001; Santegoeds et al. 1999). Here, a factor 2 excess lactate compared to nitrate was sufficient to maintain this structure. As most selenium containing streams are depleted in electron donor and its addition is the primary factor in the operating costs (Zhang et al. 2008), this excess should be minimized. As a result, utilization of immobilized cells alone might be more feasible, as less electron donor is consumed by non-selenium converting organisms. 
Acknowledgments The authors would like to thank Ir. Dai Yue for her contribution to the laboratory reactor operations. This work was supported by the European Union within the Marie Curie Excellence TEAM Grant "Novel biogeological engineering processes for heavy metal removal and recovery" (MEXT-CT-2003-509567).

Open Access This article is distributed under the terms of the Creative Commons Attribution Noncommercial License which permits any noncommercial use, distribution, and reproduction in any medium, provided the original author(s) and source are credited.

\section{References}

Amweg EL, Stuart DL, Weston DP (2003) Comparative bioavailability of selenium to aquatic organisms after biological treatment of agricultural drainage water. Aquat Toxicol 63(1):13-25

Boon N, De Gelder L, Lievens H, Siciliano SD, Top EM, Verstraete W (2002) Bioaugmenting bioreactors for the continuous removal of 3-Chloroaniline by a slow release approach. Environ Sci Technol 36(21):4698-4704

El Fantroussi S, Agathos SN (2005) Is bioaugmentation a feasible strategy for pollutant removal and site remediation? Curr Opin Microbiol 8(3):268-275

Enright A-M, Collins G, O'Flaherty V (2007) Temporal microbial diversity changes in solvent-degrading anaerobic granular sludge from low-temperature $\left(15^{\circ} \mathrm{C}\right)$ wastewater treatment bioreactors. Syst Appl Microbiol 30(6):471-482

Frankenberger WT, Amrhein C, Fan TWM, Flaschi D, Glater J, Kartinen E, Kovac K, Lee E, Ohlendorf HM, Owens L et al (2004) Advanced treatment technologies in the remediation of seleniferous drainage waters and sediments. Irrig Drain Syst 18 (1): $19-42$

Gonzalez-Gil G, Lens PNL, Van Aelst A, Van As H, Versprille AI, Lettinga G (2001) Cluster structure of anaerobic aggregates of an expanded granular sludge bed reactor. Appl Environ Microbiol 67(8):3683-3692

Green FB, Lundquist TJ, Quinn NWT, Zarate MA, Zubieta IX, Oswald WJ (2003) Selenium and nitrate removal from agricultural drainage using the AIWPS (R) technology. Water Sci Technol 48(2):299-305

Hamilton SJ (2004) Review of selenium toxicity in the aquatic food chain. Sci Total Environ 326(1-3):1-31

Hockin SL, Gadd GM (2003) Linked redox precipitation of sulfur and selenium under anaerobic conditions by sulfate-reducing bacterial biofilms. Appl Environ Microbiol 69(12):7063-7072

Kimura M (1980) A simple method for estimating evolutionary rates of base substitutions through comparative studies of nucleotide sequences. J Mol Evo 16(2):111-20

Leenen EJTM, Dos Santos VAP, Grolle KCF, Tramper J, Wijffels RH (1996) Characteristics of and selection criteria for support materials for cell immobilization in wastewater treatment. Water Res 30:2985-2996

Lenz M, Lens PNL (2009) The essential toxin: the changing perception of selenium in environmental sciences. Sci Total Environ doi:10.1016/j.scitotenv.2008.07.056.

Lenz M, Gmerek A, Lens PNL (2006) Selenium speciation in anaerobic granular sludge. Int J Environ Anal Chem 86(9):615-627

Lenz M, Smit M, Binder P, van Aelst AC, Lens PNL (2008a) Biological alkylation and colloid formation of selenium in methanogenic UASB reactors. J Environ Qual 37(5):1691-1700

Lenz M, van Hullebusch ED, Hommes G, Corvini PFX, Lens PNL (2008b) Selenate removal in methanogenic and sulfate-reducing upflow anaerobic sludge bed reactors. Water Res 42(8-9): 2184-2194
Maidak BL, Olsen GJ, Larsen N, Overbeek R, McCaughey MJ, Woese CR (1996) The Ribosomal Database Project (RDP). Nucl Acids Res 24(1):82-85

Morita M, Uemoto H, Watanabe A (2007) Reduction of selenium oxyanions in wastewater using two bacterial strains. Eng Life Sci $7(3): 235-240$

Muyzer G, De Waal EC, Uitterlinden AG (1993) Profiling of complex microbial populations by denaturing gradient gel electrophoresis analysis of polymerase chain reaction-amplified genes coding for 16 S rRNA. Appl Environ Microbiol 59(3):695-700

Oremland RS, Blum JS, Bindi AB, Dowdle PR, Herbel M, Stolz JF (1999) Simultaneous reduction of nitrate and selenate by cell suspensions of selenium-respiring bacteria. Appl Environ Microbiol 65(10):4385-4392

Oremland RS, Herbel MJ, Blum JS, Langley S, Beveridge TJ, Ajayan PM, Sutto T, Ellis AV, Curran S (2004) Structural and spectral features of selenium nanospheres produced by Se respiring bacteria. Appl Environ Microbiol 70(1):52-60

Presser TS (1994) Geologic origin and pathways of selenium from the California coast ranges to the west-central San Joaquin Valley. In: Frankenberger WT (ed) Selenium in the environment. Marcel Dekker, New York, pp 139-155

Presser TS, Luoma SN (2007) Forecasting selenium discharges to the San Francisco Bay-delta estuary: ecological effects of a proposed San Luis Drain extension. Available at http://pubs.usgs.gov/pp/ p1646/pdf/pp1646.pdf

Sabaty M, Avazeri C, Pignol D, Vermeglio A (2001) Characterization of the reduction of selenate and tellurite by nitrate reductases. Appl Environ Microbiol 67(3-12):5122-5126

Saitou N, Nei M (1987) The neighbor-joining method: a new method for reconstructing phylogenetic trees. Mol Biol Evol 4(4):406-25

Santegoeds CM, Damgaard LR, Hesselink G, Zopfi J, Lens P, Muyzer G, de Beer D (1999) Distribution of sulfate-reducing and methanogenic bacteria in anaerobic aggregates determined by microsensor and molecular analyses. Appl Environ Microbiol 65(10):4618-4629

Schröder II (1997) Purification and characterization of the selenate reductase from Thauera selenatis. J Biol Chem 272(38):2376523768

Stolz JF, Ellis D, Blum JS, Ahmann D, Lovley D, Oremland R (1999) Sulfurospirillum barnesii sp. nov. and Sulfurospirillum arsenophilum sp. nov., new members of the Sulfurospirillum clade of the $\varepsilon$ proteobacteria. Int J Syst Bacteriol 49(3):1177-1180

Stolz JE, Basu P, Santini JM, Oremland RS (2006) Arsenic and selenium in microbial metabolism. Annu Rev Microbiol 60:107-130

Swofford DL (2001) Phylogenetic analysis using parsimony (and other methods). Sinauer, Sunderland, MA

Taggart MA, Figuerola J, Green AJ, Mateo R, Deacon C, Osborn D, Meharg AA (2006) After the Aznalcollar mine spill: arsenic, zinc, selenium, lead and copper levels in the livers and bones of five waterfowl species. Environ Res 100(3):349-361

Thompson JD, Gibson TJ, Plewniak F, Jeanmougin F, Higgins DG (1997) The CLUSTAL X windows interface: flexible strategies for multiple sequence alignment aided by quality analysis tools. Nucl Acids Res 25(24):4876-82

Tucker MD, Barton LL, Thomson BM (1998) Reduction of Cr, Mo, Se and $\mathrm{U}$ by Desulfovibrio desulfuricans immobilized in polyacrylamide gels. J Ind Microbiol Biotechnol 20(1):13-19

USEPA (2002) National recommended water quality criteria. Available at http://www.epa.gov/waterscience/criteria/wqcriteria.html.

Vallero MVG, Sipma J, Lettinga G, Lens PNL (2004) High-rate sulfate reduction at high salinity (up to $90 \mathrm{mS} . \mathrm{cm}^{-1}$ ) in mesophilic UASB reactors. Biotechnol Bioeng 86(2):226-235

van Langerak EPA, Ramaekers H, Wiechers J, Veeken AHM, Hamelers HVM, Lettinga G (2000) Impact of location of $\mathrm{CaCO}_{3}$ precipitation on the development of intact anaerobic sludge. Water Res 34(2):437-446 
Watts CA, Ridley H, Dridge EJ, Leaver JT, Reilly AJ, Richardson DJ, Butler CS (2005) Microbial reduction of selenate and nitrate: Common themes and variations. Biochem Soc Trans 33(1):173-175

Weijma J, Stams AJM, Pol LWH, Lettinga G (2000) Thermophilic sulfate reduction and methanogenesis with methanol in a high rate anaerobic reactor. Biotechnol Bioeng 67(3):354-363

Wu L (2004) Review of 15 years of research on ecotoxicology and remediation of land contaminated by agricultural drainage sediment rich in selenium. Ecotoxicol Environ Saf 57(3):257-269
Zhang YQ, Frankenberger WT (2006) Removal of selenate in river and drainage waters by Citrobacter braakii enhanced with zerovalent iron. J Agric Food Chem 54(1):152-156

Zhang Y, Zahir ZA, Frankenberger WT Jr (2004) Fate of colloidalparticulate elemental selenium in aquatic systems. J Environ Qual 33(2):559-564

Zhang Y, Okeke BC, Frankenberger WT Jr (2008) Bacterial reduction of selenate to elemental selenium utilizing molasses as a carbon source. Bioresour Technol 99(5):1267-1273 